Injury control in South America

\section{Injury control in South America: the art and science of disentanglement}

\section{Blank}

Injury control in a vast number of the American people remains in the 20th century while the injury pandemic shows a 21 st century face

W hile musing upon the request to write an indigenous pediatrician's perspective of the state of play of injury control in South America, particularly as to why matters remain at a rather primitive level and what could be done to move things along, I was struck by this news item: a newspaper in my hometown in southern Brazil reported that a unidentified motorcyclist had fired two gunshots at a brand new mobile speed camera. This camera had replaced a similar one that had been destroyed a month before by two enraged characters armed with iron bars. $^{\text {wl w2 }}$ This seemingly simple account actually offers insights into a variety of issues: undue weapon carrying, speeding vehicles, novel traffic calming strategies, newish high tech devices, meager safety knowledge discrimination, sheer public unawareness, violence at-large, and-of course-a middle income developing country with mostly inconsistent and inequitable public health priorities. Does this sound too entangled for the ordinary reader's liking? Well, bienvenido a Sudamérica!

\section{THE USUAL GRIM FIGURES, WITH SOME NASTY PARTICULARS}

The injury problem in South America, as worrisome as in the rest of the world, bears some specific circumstances that are worthy of attention. First, up to 29 years, injuries account for nearly six million disability adjusted years of life lost each year-around $17 \%$ of the burden of disease. ${ }^{1}$ This means we face a graver public health problem than most.

Second, although the region is by and large free from wars, interpersonal violence has been a frighteningly growing cause of death and disablement from the age of 5 through adolescence. ${ }^{1-3}$ Figure 1 shows death rates associated with the main causes of injury in selected countries. While homicide rates may be quite similar to those of high income nations in exceptional cases like
Argentina and Chile, most figures are disturbing, particularly those from Brazil and Colombia, which are three to six times greater than those from the most violent of the developed countries. $^{24}$

A third circumstance that stands out is the absolute predominance of male victims: even if we disregard homicides, females are consistently three to four times less likely to die from injury than males. This is a significantly larger gender gap than usual. If we focus on homicides, the disparity is even more stark; for instance, the odds of Colombian or Brazilian males rather than females being killed are over 10 to one! ${ }^{2}$ Though most other countries are much less violent, the broad prenoticeable in all age ranges and types of injury, particularly drowning and self inflicted injuries.

Road traffic injuries are somewhat peculiar in South America, with both distinctive features and many shared with either developed or primitive societies. As in high income countries, traffic crashes are a leading cause of death among children $0-4$ years-which is not usually the case in less developed regions-and remains the number one killer in school age children and teenagers. ${ }^{1}$ On the other hand, as in most poor countries, South American traffic is marked by quite diverse road usage, including the predominance of pedestrians and the presence-sometimes massive-of motorcycles, bicycles, and animal drawn vehicles. ${ }^{5}$ Whereas established economy regions have experienced a steady downward trend in traffic related death rates, over the past few decades, South America has generally followed the rest of the world's divergent upward trend. In spite of that, many municipalities managed to stabilize the number of deaths on the roads through strict enforcement of safety laws, usually with a narrow focus on issues like seat belts, speed control, or cell phone bans. ${ }^{6}$ dominance of male victims is quite
Finally, fig 1 shows the inordinate rate of injuries with unknown intent, ranging from $15 \%$ to $30 \%$ (compared with developed countries' rates of about $2 \%)$, undoubtedly because the gathering of data in too many South American settings is incomplete, often based on extrapolations, or simply unreliable. Given that data concerning non-mortal injuries are even less reliable, it is clear that future injury control measures must call for the serious commitment of professionals and governments to improving research and official statistics from which to derive priorities.

\section{A FEW REFLECTIONS ON THE ALLEGED CAUSES}

It has often been said that people in poor countries are at greater risk for injury because of the defective adaptation to modern technologies and products without the attention to safety standards and attitudes. In fact, it is logical to relate injury risk to overcrowded and vulnerable dwellings, pedestrians on insecure roads, faulty means of transport, small arms proliferation, and workplaces not adhering to safety standards. Such reasoning leads to the empirical assumption of manifold deterrents to injury control in all of South America: prevailing functional illiteracy and less than effective media that hinder awareness; weak community organization and communication between sectors of activity; low priority support from governments or lack of regulatory authority; fragmentary ongoing social and political processes; scanty financial resources; scarcity of competent technical advisors; and more environmental and product hazards. Moreover, in most countries many social determinants, like unemployment and lack of support for agriculture, promote the clustering of millions of inhabitants in huge and distorted cities, with all their inherent inadequacies.

Nevertheless, many have cautioned against unsound generalizations about the influence of geographic and cultural transitions, as well as socioeconomic differences, on injury risks. ${ }^{7-9}$ Several studies have cast doubt on the contribution of poverty alone to injury rates, suggesting that sharing of space and proximity to relatives could be regarded as positive values, that household crowding could provide more opportunities for supervision, that children from affluent families may be at increased risk of recreational injury, and that children of single parents might not face a greater risk for injury. ${ }^{10-14}$ There is also the ongoing issue of the allegedly detrimental effect of the use of the word "accident" to injury control efforts, particularly within the realm of Latin 


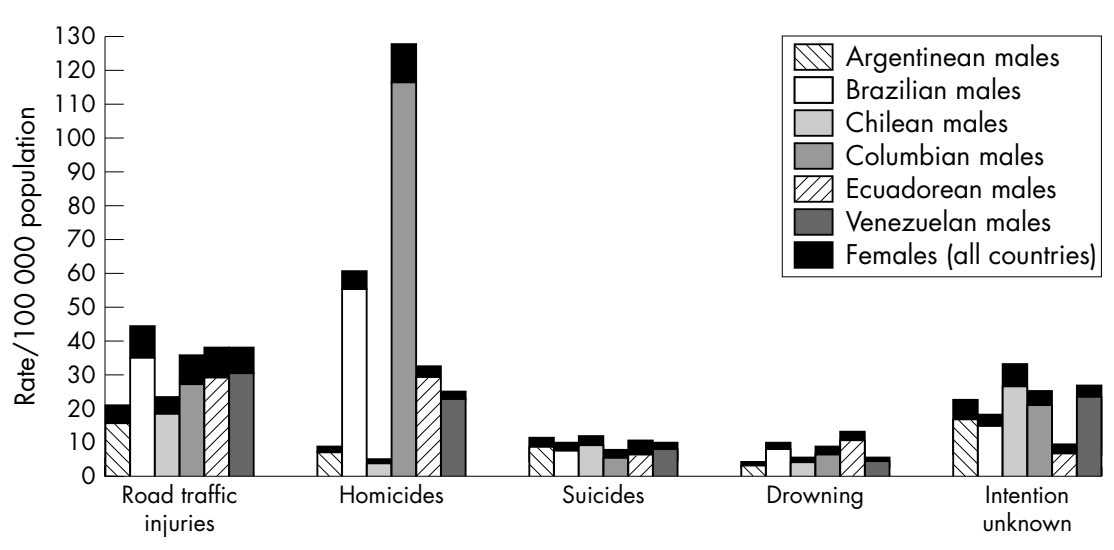

Figure 1 Age standardized injury related mortality rates for selected South American countries (per 100000 population, years 1997-99) Source: Pan American Health Organization/Special Program for Health Analysis, Technical Information System (available at: www.paho.org/english/ $\mathrm{ad} / \mathrm{dpc} / \mathrm{nc} /$ lesion.htm).

languages, in which the term "injuria" bears a strong connotation of moral offense. In spite of the prevailing belief that the use of the word accident is at least part of the reason people (and especially governments) do not view injuries as they do diseases, ${ }^{15}$ context specific research is still needed to clarify the practical implications; and the same applies to the complex etiology of injuries.

It is wise to bear in mind that none of the South American countries has yet accomplished the difficult epidemiologic transition from the stage of rising trends of injury proportional mortality to that in which injury control starts to succeed. ${ }^{16}{ }^{17}$ To do so-and to grasp the causes of South America's injury problem-will take much international cooperation involving true exchange, not only transfer, of research knowledge and experiences, successful or not.

\section{ACADEMIA IN LOW GEAR...}

What are South American researchers doing about this huge public health problem? Since this journal is among the top international journals with an exclusive general injury prevention focus, a hard look at its contents should surely point to the answer. From its launch, Injury Prevention has published only three original articles from South America: Delgado et al showed that crowding, poverty, and poor maternal education were major risk factors for burns in Peruvian children. ${ }^{\text {w3 }}$ Liberatti et al presented a before-and-after study of the inception of the new Brazilian traffic code, and concluded that it had been effective in increasing the use of safety equipment and decreasing the number of young drivers under the influence of alcohol. ${ }^{\mathrm{w}}{ }^{4}$ Fonseca et al, also from Brazil, showed that diaries could provide better information than retrospective methods in assessing injuries among preschool children. ${ }^{\mathrm{w} 5}$ In a letter, I noted that the new Brazilian traffic code was one of the few available laws requiring children under 10 to travel in the back seat and to use a safety device. ${ }^{\mathrm{w} 6}$ Apart from that, there were only seven cursory citations of three of Argentina, and one of Peru, either in articles or in general sec-

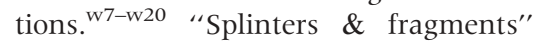
commented on one Colombian study that described a standardized road injury reporting system; one more study on the effectiveness of the new Brazilian traffic code; and another Brazilian study that documented that three quarters of injured children were not alone. ${ }^{\mathrm{w} 15}$ w16 The sole South American entry in 10 years of "News and notes" referred to the Argentinean non-profit organization "Luchemos por la Vida", which promotes traffic safety awareness. ${ }^{\text {w17 }}$ Uruguay was remotely alluded to in an editorial citation of Uruguayan journalist Eduardo Galeano's account on how his continent's transportation infrastructure had been developed to drain its wealth out to the colonial economy. ${ }^{\mathrm{w} 2 \mathrm{l}}$ None of the remaining countries-Bolivia, Ecuador, French Guiana, Guyana, Paraguay, Suriname, and Venezuela-was ever directly cited.

The lack of citation could be due to the difficulty of Spanish and Portuguese speaking authors to publish in English. However, a search through the main South American medical databases, LILACS $^{\mathrm{w} 22}$ and SciELO, ${ }^{\mathrm{w} 23}$ using the terms "injury", "accident" and "child", over the past two years, yielded only 13 articles from Brazil, ${ }^{\text {w24-w36 }} 10$ from Argentina, ${ }^{\mathrm{w} 37-\mathrm{w} 46}$ and one from Chile. ${ }^{\mathrm{w} 47}$ All papers were descriptive studies, reviews, editorials, and case reports; I did not find any intervention evaluation. The intriguing absence of articles from Brazil, five of Colombia, four of Chile, Colombia, home of the Andean Net of
Violence Prevention, prompted me to perform a manual search in the official journal of the Colombian Pediatric Society; it did not retrieve any paper on injuries. The leading role of Brazil and Argentina is probably due to the continuous awareness raising actions of pediatric societies, as well as to the recent surge of development of postgraduate courses, which have been strongly promoting scientific publishing. Knowledge exchange brought about by the Group of Editors of Pediatric Journals of the South Cone $\mathrm{w}^{\mathrm{w} 48}$-one of whose most fruitful achievements is the yearly publication of selected original articles from Argentina, Brazil, Chile, Uruguay, Paraguay, and Bolivia-also merits remark.

A perusal of the abstract book of the Vienna World Conference revealed that $3.8 \%$ of the 1538 scientific presentations were from South America; mostly mortality trend analyses, descriptive epidemiology, safety knowledge evaluation, communication strategies, description of programs, appraisal of legislation, and public health policies. Again, there were only seven intervention studies. ${ }^{\mathrm{W} 49-w 55}$ This is too small a contribution, even if we take into account that fewer than $10 \%$ overall of these conferences' papers show evaluations. ${ }^{18}$ Thirty two presentations came from Brazil; Colombia had 24 presentations; and Chile and Uruguay appeared with one each. I do not have an explanation for the absence of Argentina. At any rate, it is imperative that these materials be published in media that are more accessible to broader audiences.

My overall conclusion is that injury research in South America is quite deficient, given the enormous toll of the injury problem. ${ }^{19}$ Indeed, to turn injury control into a lasting research priority, we simply must evolve to a further socioeconomic stage, which allows training of enough professionals and proper provision of funds. Until then, help from developed countries is indispensable. Also, journal editors could be further persuaded to publish reports with less than ideal methodological soundness in the name of fostering research in developing regions. As has already been stated in this journal, learning in public health is best promoted by the critical sharing of evidence, instead of censoring evidence that is less than perfect. ${ }^{20}$

\section{THINGS ARE LOOKING UP (SORT OF)}

The past two decades saw the flourishing of a number of non-governmental organizations devoted to different enterprises in safety promotion, mainly traffic injury prevention and violence reduction. These have played a major 
part in stimulating public awareness, gathering impartial information, influencing implementation of policies, lobbying for the passage of effective laws, and-above all-bringing about creative innovations. For instance, the organization Vida Urgente chauffeurs teenagers from late night parties, rendering high risk driving a minor concern. ${ }^{\mathrm{w} 56}$ Figure 2 shows an example of such productive Third Sector organizations. The websites of some of the most relevant of the Third Sector organizations, which all readers are encouraged to visit, can be found at Injury Prevention online. ${ }^{\text {w56-w70 }}$ The bad news is that however effective these organizations may be in their particular fields, they lack communication and interdisciplinary work, which would greatly enhance their actions. Since South American media-some of whose campaigns have special meritsdo a good job overall in promoting public awareness and education, communication professionals could certainly be stimulated to help more in fostering the interplay between non-governmental organizations.

Government actions are mixed: most countries perceive injuries as a significant public health problem, but only half of them have a national injury prevention strategy or a consultative group. $^{21}$ In part, this is due to the prevailing political instability and competing interests, although all South American countries have got rid of autocratic regimes whose actions were not always to the people's advantage. At any rate, there are some good examples to note, such as the Argentine Pediatric Trauma Program, ${ }^{22}$ the Brazilian National Policy of Reduction of Injury Morbidity and Mortality, ${ }^{23}$ and the new Colombian TransMilenio mass transport system. $^{24} \mathrm{~A}$ more recent instance of

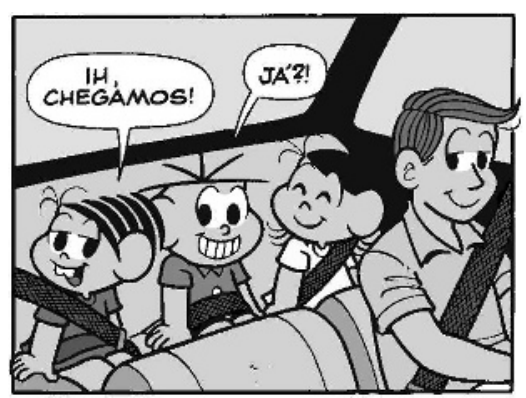

Figure 2 Monica and friends promote the Brazilian Traffic Code, which mandates children under 10 to ride in rear seat and with an age appropriate safety device. These characters - the South American counterparts of Charlie Brown \& Co-deserve recognition for their long standing traffic safety promotion work, which is the epitome of the Third Sector injury control activities (published with permission; copyright 1996 Mauricio de Sousa Produções). public enthusiasm for a government cause is the massive support given to the new Brazilian Disarmament Statute, which restricts and regulates the use of weapons. In the first couple of weeks after the law came into force by a presidential decree, over 20000 guns were turned in to the authorities.

To sum up, in spite of financial constraints and competing priorities, the concern of societies and governments about injuries has grown steadily in South America and has brought about positive initiatives. Unfortunately, the market sector is reluctant to get involved, necessitating dependence on developed nations for the foreseeable future.

\section{STEPPING INTO THE 21ST CENTURY}

In summary, it will take a great deal of science and much art to disentangle the intricacies of all sociocultural determinants and control measures of injury in South America. However, the question remains: what exactly can (must?) be done to move things along? In addition to the various suggestions above (improving research and official statistics, context specific and action driven research, international cooperation in exchanging research knowledge and experiences, more accessible publications, more inclusive publishing policies, training more professionals, strict enforcement of focused safety laws, involving the market sector), I urge the following pragmatic considerations: First, it is imperative that we set first order priorities and countermeasures locally and immediately. Second, we must take teamwork seriously and strive for true interdisciplinary action. Third, we should favor the so-called bottom-up approach, in which communities assume greater responsibility for both collective and individual safety. It is necessary to adapt the original safe community concept to our reality, acting at the neighborhood level, so as to turn many large unsafe cities into a myriad of safe communities. Fourth, we should devise strategies using a systems approach, in which the environment helps people to cope with day-to-day threats so that their behavior does not lead to injury.

Lastly, although this editorial was commissioned with the suggestion that I didn't dwell on the issue of low income, it is difficult not to consider that in order to slash the injury related burden to levels that approximate those of developed countries it is essential that the whole of South America evolve to a higher and more equitable socioeconomic stage. Therefore, even if this is beyond the direct control of the injury community, everyone must play their part in a collective effort to foster democratic institutions, along with all the other actions mentioned, lest we remain trapped in the 20th century, while the injury pandemic shows a sinister 21 st century face.

Injury Prevention 2004;10:321-324.

doi: 10.1136/ip.2004.006908

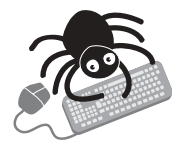

Extra references $(w)$ appear on http://www. injuryprevention.com/ supplemental

Correspondence to: Professor Danilo Blank, Department of Pediatrics, Universidade Federal do Rio Grande do Sul School of Medicine, Porto Alegre, RS, Brazil; blank@orion.ufrgs.br

\section{REFERENCES}

1 Peden M, McGee K, Krug E, eds. Injury: a leading cause of the global burden of disease, 2000. Geneva: World Health Organization, 2002.

2 Pan American Health Organization. Statistics on homicides, suicides, accidents, injuries. and attitudes towards violence. Available at: http:// www.paho.org/common/

Display. asp? Lang $=E \&$ RecID $=3236$ (accessed 13 May 2004).

3 Krug EG, Dahlberg LL, Mercy JA, et al, eds. World report on violence and health. Geneva: World Health Organization, 2002.

4 National Center for Injury Prevention and Control. WISQARS Fatal injuries: mortality reports. Available at: http://webappa.cdc.gov/ sasweb/ncipc/mortrate.html laccessed 18 July 2004)

5 Forjuoh SN. Traffic-related injury prevention interventions for low-income countries. Ini Control Saf Promot 2003;10:109-18.

6 Nantulya VM, Reich MR. Equity dimensions of road traffic injuries in low- and middle-income countries. Inj Control Saf Promot 2003; 10:13-20.

7 Zwi AB. Injury control in developing countries: context more than content is crucial. Inj Prev 1996;2:91-2.

8 Mohan D. Injuries in less industrialised countries: what do we know? Inj Prev 1997;3:241-2.

9 Marcin JP, Schembri MS, He J, et al. A population-based analysis of socioeconomic status and insurance status and their relationship with pediatric trauma hospitalization and mortality rates. Am J Public Health 2003:93:461-6.

10 Teixeira AMFB. [Accident-related morbidity in children under ten years in Pelotas, RS: prevalence and characterization of accidents.] [Dissertation.] Pelotas: UFPEL, 1992.

11 Fonseca SS, Victora CG, Halpern R, et al. [Risk factors for accidental injuries in preschool children.] J Pediatr (Rio J) 2002;78:97-104.

12 Addor V, Eggimann BS. Population-based incidence of injuries among preschoolers. Eur J Pediatr 1996;155:130-5.

13 Agran PF, Winn DG, Anderson CL, et al. Family, social, and cultural factors in pedestrian injuries among Hispanic children. Inj Prev 1998:4:188-93.

$14 \mathrm{Ni} \mathrm{H}$, Barnes P, Hardy AM. Recreational injury and its relation to socioeconomic status among school aged children in the US. Inj Prev 2002;8:60-5.

15 Stone DH, Jarvis S, Pless B. The continuing global challenge of injury. BMJ 2001;322:1557-8.

16 Plitponkarnpim A, Andersson R, Jansson B, et al. Unintentional injury mortality in children: a priority for middle income countries in the advanced stage of epidemiological transition. Inj Prev 1999;5:98-103

17 van Beeck EF, Borsboom GJ, Mackenbach JP. Economic development and traffic accident 
mortality in the industrialized world, 1962-1990. Int J Epidemiol 2000;29:503-9.

18 Smith CA, Shannon HS. How much science is there in injury prevention and control? Inj Prev 2003:9:89-90.

19 Blank D. [Injury prevention and control: will we or will we not step out of the twentieth century?] J Pediatr (Rio J) 2002;78:84-6.
20 Moller J. Reconsidering community based interventions. Inj Prev 2004;10:2-3.

21 Bangdiwala S, Viadro C. A review of national policies and programs to prevent unintentional injuries in the Americas Ini Control Saf Promot 2000:7:15-27.

22 Inon AE, Haller JA Jr. Caring for the injured children of our world: a global perspective. Surg Clin North Am 2002;82:435-45.
23 Ministerio da Saude. Secretaria de Politicas de Saude. [National Policy of Reduction of Accident and Violence Morbimortality.] Rev Saude Publica 2000:34:427-30.

24 Peden M, Scurfield R, Sleet $D$, et al, eds. World report on road traffic injury prevention. Geneva: World Health Organization, 2004
Advocacy

\section{Evidence based advocacy}

\section{E Friedlaender, $\mathrm{F}$ Winston}

\section{The academic clinician scientist's important role in translating research into action}

$\mathrm{E}$ vidence based advocacy integrates the otherwise independent but overlapping efforts of clinicians, academics, epidemiologists, public health officials, and policymakers to apply scientific principles to widespread health promotion and prevention initiatives. We argue here that advocacy efforts lie within academic medical responsibilities, in part because health care academics lend credibility, as well as inspiration and imagination to these worthwhile pursuits, but more so because it concludes a professional obligation to those in our care by translating research to action. Just as rigorous science builds the evidence base for change, rigorous efforts and their evaluation are necessary to ensure that this evidence will be translated into change.

\section{SUCCESSFUL MODELS OF ADVOCACY}

Perhaps the most striking historical example of the impact of individual academic clinician scientists on advocacy efforts has been in the containment and control of poliomyelitis. International public sector and private sector partnerships among government agencies and local health care providers ensure routine immunizations, offer supplementary immunizations, and implement careful surveillance of the occurrence of acute flaccid paralysis. Recent efforts have reduced the burden of polio globally by greater than $99 \%$ since 1988. ${ }^{1}$ Academic clinician scientists, Dr Jonas Salk at the University of Pittsburgh and Dr Albert Sabin at Cincinnati Children's Hospital, pioneered broad polio immunization efforts in the 1960s.
Health care providers have also been instrumental in shaping and implementing advocacy efforts related to smoking cessation. Dr Luther L Terry, Surgeon General of the United States Public Health Service, released a landmark report from the Surgeon General's Advisory Committee on Smoking and Health on 11 January 1964, providing the initial scientific evidence linking smoking to cancer and other serious diseases. ${ }^{2}$ More recently, the Joint Committee on Smoking and Health issued a Special Report outlining global physician responsibility in the control of smoking related illness: clinicians ought to ensure that counseling and pharmacological management for nicotine addiction are readily available to all patients. ${ }^{3}$ Since 1965, the rate of adult current smokers has dropped from $41.9 \%$ to $23.2 \%$ in $2000 .{ }^{4}$ Advocacy driven by healthcare professionals can have a profound impact on healthy behaviors.

Individual successes based on the efforts of healthcare professionals within the field of injury prevention deserve similar accolades, but fall far short of addressing the burden of injury. Child passenger safety advocacy, initially spearheaded by a pediatrician and academic/clinician from Tennessee, Robert Sanders, has had a tremendous impact on protecting children in crashes. Since Sanders began his advocacy to get children into appropriate child safety seats and booster seats, all 50 states and the District of Columbia have enacted laws requiring child restraints for very young children. Through additional research from others, American Academy of Pediatrics policy statements and national and community based advocacy programs, academic clinicians have furthered the field of child passenger safety considerably. Since 2000, 28 states and the District of Columbia have upgraded their child restraint laws to protect older children with booster seat requirements and two federal laws have also been enacted to improve safety standards for children in motor vehicles. Policymakers relied on published data and testimony provided by academic clinicians. Partners for Child Passenger Safety, funded by State Farm $^{\circledR}$ at The Children's Hospital of Philadelphia began reporting national restraint use trends for children in 1999. Since then, child restraint use has increased from $49 \%$ to $65 \%$ in $2003 .{ }^{5}$ The significant increase in child restraint use in recent years has had a direct effect on motor vehicle traffic fatality statistics, which were at historic low levels for children under age 8 in 2002. ${ }^{6}$ Advocacy has stimulated tremendous increases in polio immunizations, smoking cessation, and child passenger safety. Still, objective inquiry into these fields of study must continue in order to create evidence bases available for review and translation into policies for the public good.

Further, insufficient attention has been paid to suicide, intentional injury deaths, drownings, suffocation, burns and smoke inhalation, and pedestrian injuries. Investigation into these growing public health epidemics has been on-going; however, most injury prevention research has yet to be applied to control measures.

With increasing demands on academic physicians, both clinically and academically, public health advocacy for many has become another burden rather than a responsibility. For others, failure to translate research into practice stems, in part, from hesitation by investigators, dedicated to research, to actively engage in advocacy. The common misperception that advocacy lacks scientific rigor or is not a scholarly pursuit has distanced many scientists from pursuing such activity as a core professional role. In fact, advocacy, defined as the translation of research into action, requires application of principles central to the disciplines of 
communication, education, and sociology. Armed with the skills and inspired to act, academic clinicians involved in evidence based advocacy ought to earn professional rewards in terms of academic currency as appropriate acknowledgment of and compensation for such efforts.

\section{THE ART OF ADVOCACY}

The leap from science to advocacy first requires skill in preparing a message for a target audience. Effective advocates engage others with simple and straightforward presentations supported by sound evidence. Physicians are well positioned to adopt the role of advocate and promote the interests of their patients to those who can effect change. Medical education and training prepared them for this role: as scientists, they can evaluate and interpret the evidence; as clinicians, on a daily basis, they deliver complex messages to a lay audience, their patients. Further, clinicians are looked to as the "voice of reason", the practical scientist who presents balanced recommendations based on evidence (that is, a treatment plan). The following discussion serves as a guide to crafting and disseminating a message, the bedrock of evidence based advocacy.

\section{(1) Choose a position that is grounded in science}

Thoroughly review the existing body of literature on your issue to ensure that your position is rational and defensible. If the research is lacking, conduct the necessary studies to define the problem and offer evidence based solutions. Your advocacy stance should be an outgrowth of available, current science. Struggle with your position. Challenge yourself to ensure that you, as a scientist, believe your review and recommendation. Then, set goals for change.

\section{(2) Determine target audiences}

According to your formative research, identify the primary audience that you are targeting for a change in behavior and know who influences its members. Respected community leaders, teachers, primary care physicians, media, industry, or policymakers may already be in a position to stimulate your desired behavior change. Your most effective path may be through these secondary audiences and collaboration with them is essential.

\section{(3) Know your audience}

Tailor your discussion to those receiving your message. Your primary and secondary audiences will likely need different messages. Learn their educational background and inquire about pertinent cultural issues that may impact on how your message will be received. Acquire an understanding of and appreciation for the needs and priorities of your target population; identify how your current goals intersect with theirs. Immerse yourself in their local newspapers, listen to their community leaders, and scan the horizon for other pressing concerns competing for attention and resources.

\section{(4) Choose evidence that is appropriate for your audience} Spell out why your issue is important and how it impacts on your audience members. Identify the benefits of action as well as the dangers of inaction, choosing the evidence and points that will resonate with your audience. Most importantly, support your arguments with data that matter to the audience. Remember that business leaders and legislators often require economic data. Incorporate anecdotes to bring a tangible humanistic element to your message as long as they reflect a larger scientific truth. Speak in simple vernacular, avoiding complicated scientific expression that may distance and frustrate your listeners. One of the best ways to ensure that your message will be effective is to pilot it with representatives of your audience.

\section{(5) Choose action that is realistic for your audience}

Clearly state for your audience their role in effecting change. Establish a reasonable time commitment needed to realize your intentions, both on your part and theirs. Propose reasonable goals and highlight tasks commensurate with the interests and abilities of your audience. An audience of doctors might be charged with incorporating anticipatory guidance into their practice; an insurance company with subsidizing the cost of safety devices. Remember that proposing a small step in the right direction that will likely be successful is better than proposing more grand action for which your audience is not ready or might fail.

\section{(6) Keep your message clear and succinct}

Attempt to identify no more than three separate points that are repeatedly reinforced and reiterated to ensure clarity and emphasize the importance of your message. The first point should introduce the subject to your audience, bringing them to your issue through a topic that is familiar and relevant. The second point should include strong evidence that links the introduction to the action, drawing the audience from something familiar to serving as your agents of change. The final point should be a call to action appropriate for that audience. For all points, choose topics and evidence that will be meaningful to your audience. Remember to stay on message and not be tempted to go in directions for which you are not prepared in order to avoid losing credibility.

\section{(7) Tailor your message to the given} forum

The audience largely dictates the format: formal or informal, speech or demonstration, brief or lengthy? Consider whether a presentation is a lone opportunity to plead a case or the first in a series of interactions during which time an idea may be introduced and later developed in detail. If your time is short, begin with the requested action and then back it up with evidence: "This is what I need; now, let me tell you why". Despite the final length of your presentation, prepare for more. Your short conversation with a legislator might lead to a series of questions or to formal testimony.

Prepare rebuttals to the likely potential challenges to your proposal and encourage partnership rather than dictating and delegating responsibilities.

\section{(8) Acknowledge your limitations} and seek collaboration to strengthen your position

Although clinicians remain a powerful figure for advocacy, do not go beyond your expertise in your evidence or your advice. Remember your training and stay true to your science. Join with other professionals to add the relevant expertise. This will both strengthen your position as a rational advocate and add to your expert constituency. It is best to collaborate with a colleague from your target audience when advocating before other professionals.

\section{(9) Evaluate your efforts}

Through qualitative and quantitative methods ensure that the message that you delivered was the one that was received. Then, if possible, track the responses to your message in terms of tangible action. Based on this feedback, revise and refine your message.

\section{THE SCIENCE OF ADVOCACY}

In following these recommendations, consult and draw upon the techniques and expertise of other disciplines dedicated to the successful communication of ideas and an appreciation of the 
insights afforded by the teachings of the social sciences regarding health behaviors and behavioral modification.

For example, social marketing applies traditional marketing principles to sell adoption of safe and healthy behaviors to the public. Social marketing is customer focused: it positions a healthy behavior as desirable from a customer's perspective rather than from a public health perspective. This approach is most useful when the target audience is neither prone nor resistant to the desired behavior change. Social marketing applied to the promotion of a socially beneficial behavior change lends academic rigor to resource development, program development, health promotion, coalition building, and policy initiatives. Just as successful marketing campaigns rely on market research, social marketing is steeped in formative research and evaluation. The integration of the principles of audience segmentation, determinants of behaviors, competition, exchange, market strategy, and market research enhances any health promotion campaign. ${ }^{78}$ Similarly, media advocacy, or the use of the mass media to direct popular attention to a particular cause, improves health by influencing the greater social and political environments in which policy decisions are made. ${ }^{8}$

Utilizing behavior change theories and models regarding human behavior can help to develop and refine a strategic approach for creating a sustained behavior change. Social marketing and behavior change theories provide guidance in determining allocation of resources along a continuum of interventions that could involve any combination of education, marketing, and law/policy advocacy efforts. Education is most effective with highly motivated audiences. Law and policy advocacy may be necessary to motivate entrenched groups to adopt a healthy behavior, while social marketing can be effective at motivating those in between.

Advocacy can be an academic pursuit, dependent on peer reviewed original data, a commitment to public health, and finely tuned communication skills. In contemplating the responsibilities of the academic clinician, prioritize continued research over advocacy: be a scientist first. The advocacy should flow from the science rather than implementing scientific pursuits to support an already planned advocacy campaign. The process of advocacy cannot take hold without a substantial foundation of evidence upon which to act and against which to react. Ultimately, collaborating with appropriate stakeholders, identified and involved early in the research process, will most effectively help advance your interests later. Take the responsibility of translating the implications of scientific discovery into practice ideas and then enable others to help disseminate your message. Finally, include funds for outreach and program evaluation in your research budgets to ensure this critical step in the evolution of research into action takes place.

Academic support for the translation of research into action is essential for continued and growing successes in public health initiatives in general, and injury prevention specifically. The formal integration of evidence based advocacy into individual academic clinician experience depends upon the accessibility of educational resources instructive in the fields of communication, public health, education, sociology, biostatistics, and epidemiology along with agreement by the academic community to compensate for such efforts. However, most important, is the commitment by individual investigators to conduct sound research as the foundation for policy change and implementation.

Injury Prevention 2004;10:324-326. doi: 10.1136/ip.2004.006536

\section{Authors' affiliations}

E Friedlaender, Division of Emergency

Medicine, Department of Pediatrics, University

of Pennsylvania School of Medicine,

TraumaLink at The Children's Hospital of

Philadelphia, USA

F Winston, Division of General Pediatrics,

Department of Pediatrics, University of

Pennsylvania School of Medicine, TraumaLink at The Children's Hospital of Philadelphia, USA

Correspondence to: Dr Eron Friedlaender, Division of Emergency Medicine, Department of Pediatrics, University of Pennsylvania School of Medicine, TraumaLink at The Children's Hospital of Philadelphia, Second Floor, Main Building, Philadelphia, PA 19104, USA;

friedlaender@email.chop.edu

\section{REFERENCES}

1 Centers of Disease Control and Prevention. Progress toward poliomyelitis educationEthiopia, Somalia, and Sudan, January 2001October 2002. MMWR Morb Mortal Wkly Rep 2002;51:1070-2.

2 National Center for Chronic Disease Prevention and Health Promotion. History of the 1964 Surgeon General's report on smoking and health, Available at: http://www.cdc.gov/tobacco/ $30 y$ rsgen.htm (accessed June 2004).

3 Statement of the Joint Committee on Smoking and Health. Smoking and health: physician responsibility. Chest 1995;108:1 118-21.

4 Centers for Disease Control and Prevention. Smoking prevalence among US adults, 19652000 (from Health, United States, 2002). Available at: http://www.infoplease.com/ipa/ A0762370.html (accessed August 2004).

5 Winston F, Chen I, Elliott M, et al. Recent trends in child restraint practices in the United States. Pediatrics 2004; 113:e458-64

6 National Center for Statistics and Analysis. Early assessment: motor vehicle traffic crash fatality and injury estimates for 2002. Available at: www.nrd.nhtsa.dot/gov/pdf/nrd-30/NCSA/ PPT/2002EARelease.pdf (accessed August 2004).

7 Turning Point National Program Office. Social marketing and public health: lessons from the field. A guide to social marketing from the social marketing national excellence collaborative. University of Washington, Seattle: Turning Point National Program Office, 2003, Available at: http://www.turningpointprogram.org/Pages/ socialmkt.html (accessed May 2004).

8 Social Marketing and Health Communications. Substance abuse and mental health services administration, Available at: http:// p2001.health.org/THEORY/communications.htm (accessed May 2004).

\section{A sad departure... with many thanks to Sue Heels}

This is a brief editorial regarding Sue Heels' contribution to Injury Prevention over the past 10 years. It may come as a surprise to some of you that the journal has been in existence that long. If you have enjoyed reading it or contributing to it, Sue, who will be retiring following this issue, deserves much of your thanks. She certainly has earned my gratitude for having made life so much easier. Sue is the consummate technical editor. It is she, and others like her, who ensure that what you've written or have read is both correct and conforms to journal style. Technical editors of the unsung heroes and heroines of journal publishing. She will be greatly missed. We can only hope that her replacement is up to the task of making us all appear to be better writers (and self editors) then we really are. Thank you Sue for a job superbly done, under often very trying circumstances-Barry Pless, Editor 